\title{
Teratogenic Effects of Hydroalcoholic Extract of Capparis spinosa Leaf on Balb/c Mice
}

\author{
Davari S.A.* PhD, Miri A.H. ${ }^{1}$ PhD, Shahraki E. ${ }^{2}$ BSc
}

*Pathobiology Department, Veterinary Medicine Faculty, University of Zabol, Zabol, Iran 1Pharmacognosy Department, Pharmacy Faculty, Zabol University of Medical Sciences, Zabol, Iran ${ }^{2}$ Medicinal Plants Research Center, Zabol University of Medical Sciences, Zabol, Iran

\begin{abstract}
Aims: As a medical herb, Capparis spinosa is used in the traditional medicine. Nevertheless, its side-effects are not yet studied, especially during the pregnancy. The aim of this study was to investigate the tratogenic effects of hydro-alcoholic extract of the leaves of Capparis spinosa on the embryo of Balb/c mice.

Materials \& Methods: In the experimental method, 32 pregnant Balb/c mice were randomly divided into four groups including control and experimental groups. The experimental groups were the groups received 200, 400, and $800 \mathrm{mg} / \mathrm{kg}$ hydro-alcoholic extract doses of the leaves of Capparis spinosa. Experimental and control groups received the extract doses and urban water as 14-day gavage, respectively. The 18-day embryos, removed out of the uterus by Cesarean, were investigated in the physical deformations. Alizarin staining method was used to assess the embryonic skeletal system. Data was analyzed using one-way ANOVA and Newman-Keuls method.

Findings: There was a significant reduction in the mean weight of the pregnant mice at the $18^{\text {th }}$ day of pregnancy in $800 \mathrm{mg} / \mathrm{kg}$ extract group compared to control group $(\mathrm{p}<0.05)$. In addition, there were significant reductions in the mean height and weight of the embryos of the mice in $800 \mathrm{mg} / \mathrm{kg}$ extract group than control group $(\mathrm{p}<0.05)$. There was no embryonic physical and skeletal deformation in the experimental groups.

Conclusion: $800 \mathrm{mg} / \mathrm{kg}$ hydro-alcoholic extract of the leaves of Capparis spinosa affect height and weight of the embryos of Balb/c mice and might have tratogenic effects on embryo.
\end{abstract}

\section{Keywords}

Capparis [http://www.ncbi.nlm.nih.gov/mesh/68031484];

Teratogenesis [http://www.ncbi.nlm.nih.gov/mesh/68064793];

Mice, Inbred Balb/c [http://www.ncbi.nlm.nih.gov/mesh/68008807]

\footnotetext{
* Corresponding Author

Tel: +985434822253

Fax: +985432240735

Address: Veterinary Medicine Faculty, University of Zabol, Kilometer 2nd of Bonjar-Pardis Road, Zabol, Iran. Postal Code: 98613-35856

davari.aida1@gmail.com

Received: October 5, $2015 \quad$ Accepted: January 11, 2016 ePublished: March 5, 2016
} 
كاياريس مصارف درمانى متعددى دارند، بلهعنوان مثال كاياريس

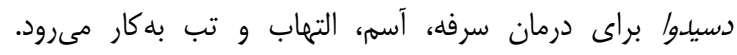

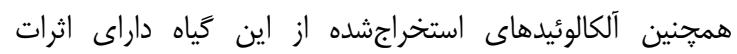

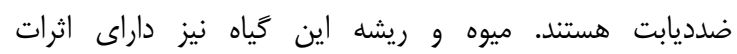

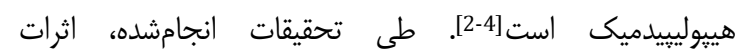

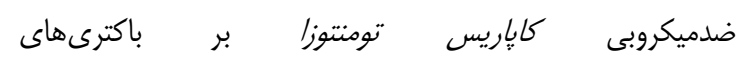

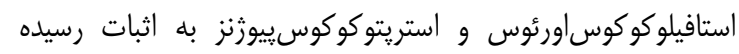

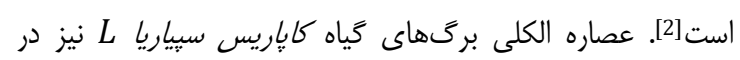

كنترل ديابت موثر هستند [5].

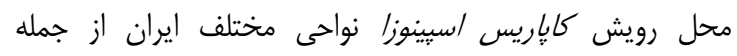

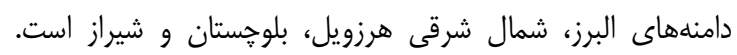

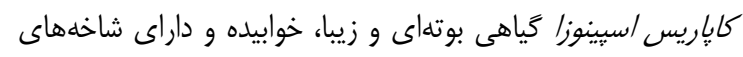

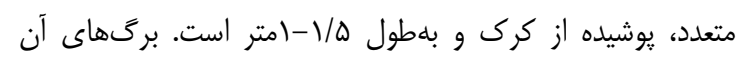

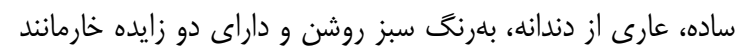

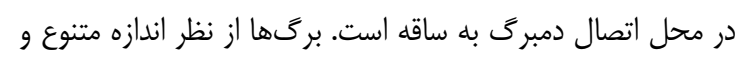

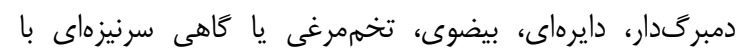

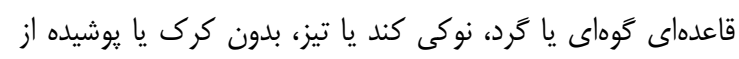

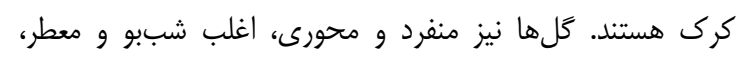

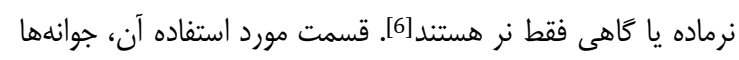

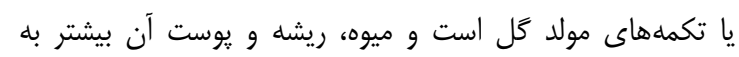
مصارف درمانى مىرسند [7].

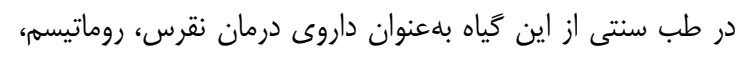

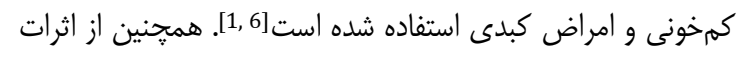

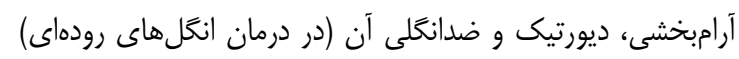

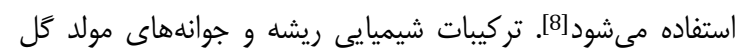

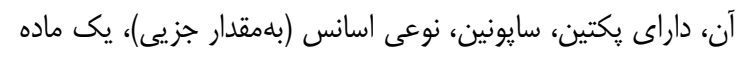

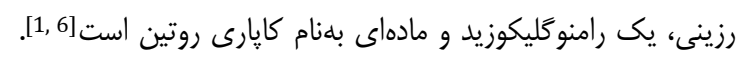

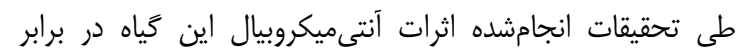

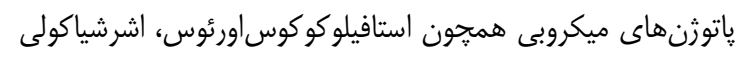

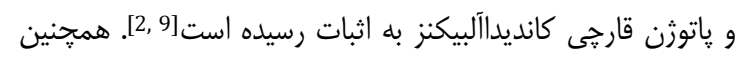

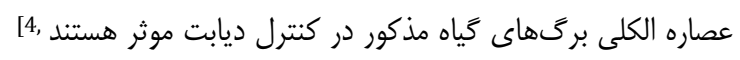

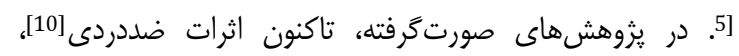

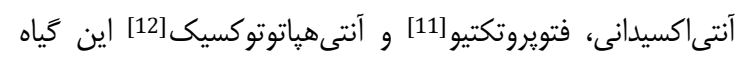

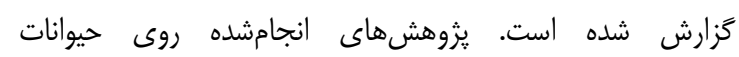

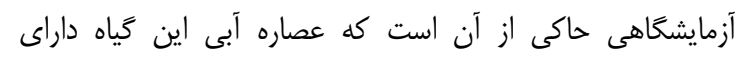

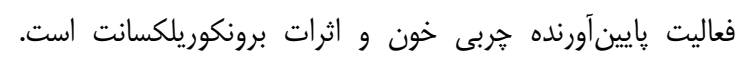

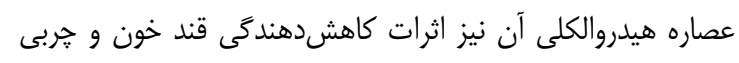

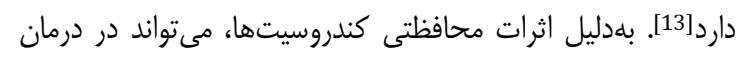

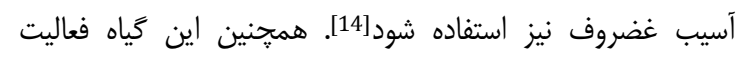
ضدسميت كبدى و التهاب مفاصل نيز دارد [110,14]. عصاره ليوفيليزه

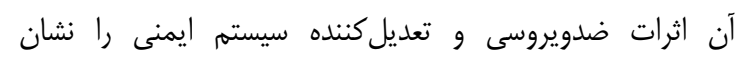

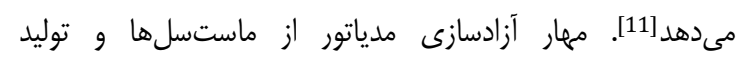

\section{اثرات تراتوزنيك عصاره هيدروالكلى برتى الت

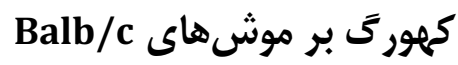

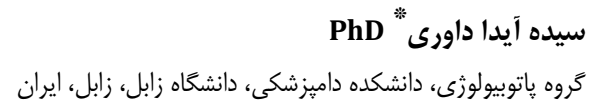

عبدالحسين ميرى PhD

كروه فارماكو كنوزى، دانشكده داروسازى، دانشكاه علوم يزشكى زابل، زابل، ايران

الهه شهركى BSc

مركز تحقيقات كَياهان دارويى، دانشخاه علوم يزشكى زابل، زابل، ايران

جكيده

اهداف: كَياه كمهورَ با نام علمى كاياريس اسبينوزا، يكى از كَياهان

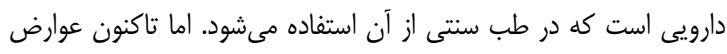

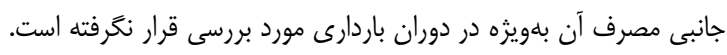

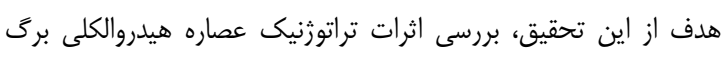

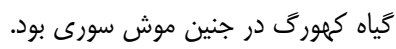

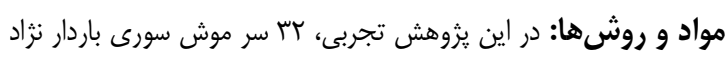

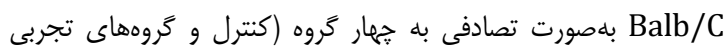

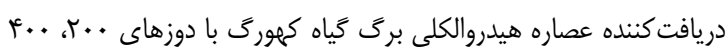

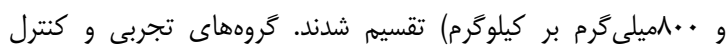

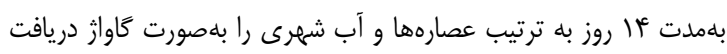

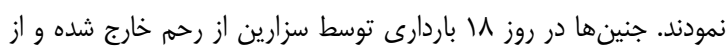

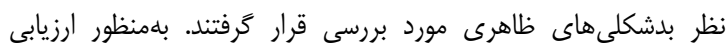

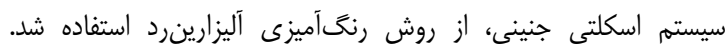

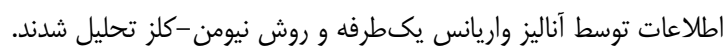

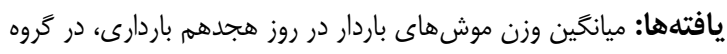

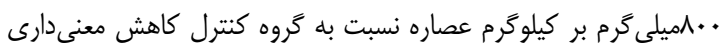

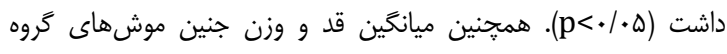

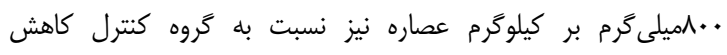

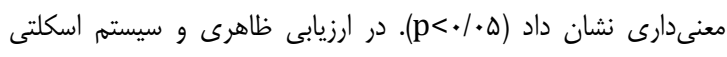

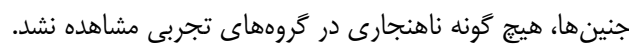

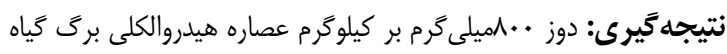

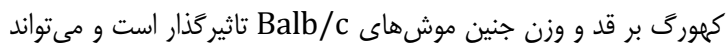

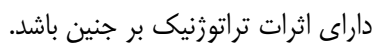

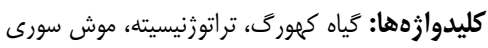

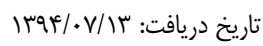

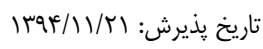
davari.aida1@gmail.com : تويسنده مسئول:

مقدمه

كهورى (Capparis spinosa)، از جنس كاياريس و متعلق به

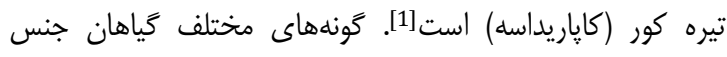

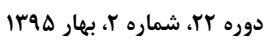

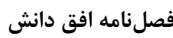




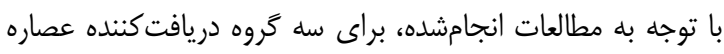

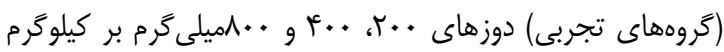

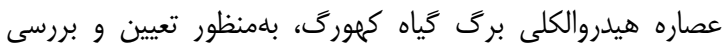

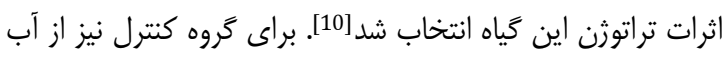

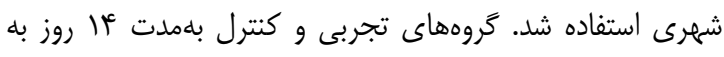

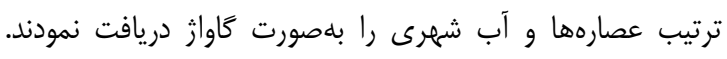

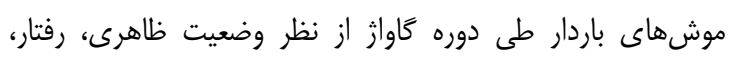

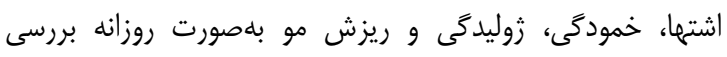

مىشدند و اطلاعات حاصله ثبت مى ريد.

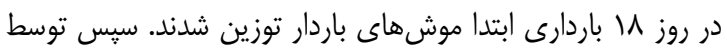

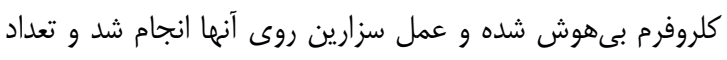

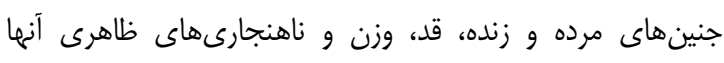

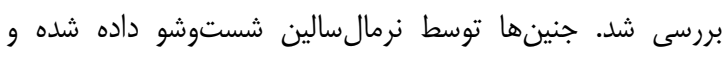

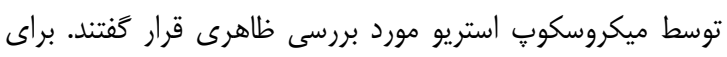

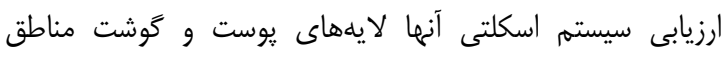

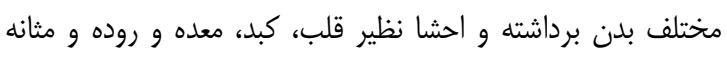

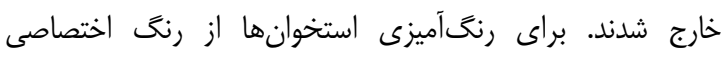

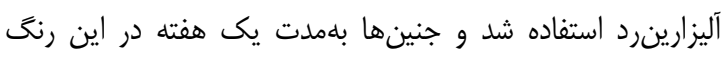

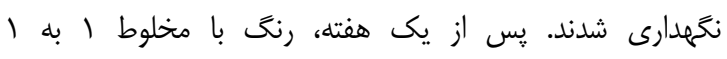

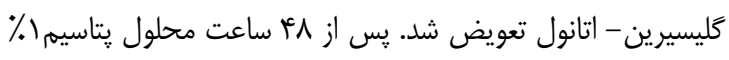

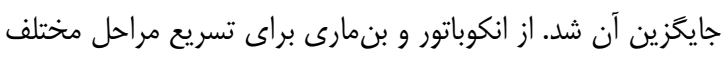

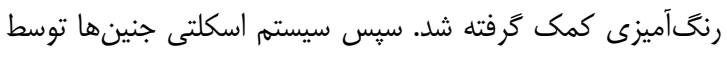

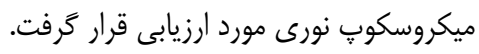

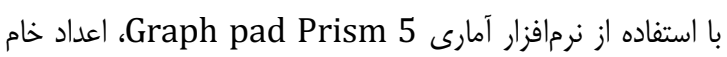

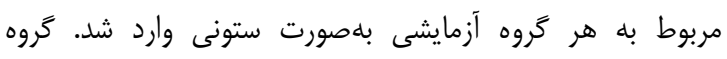

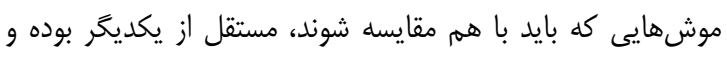

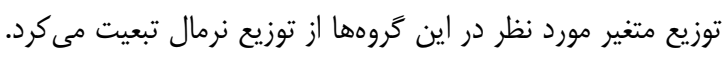

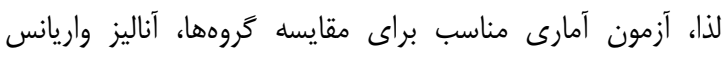

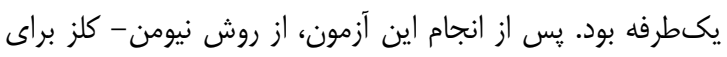
مقايسه بين گروهها استفاده شد.

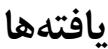

موشهاى باردار دريافتكننده عصاره، طى دوره كاواز مقدارى

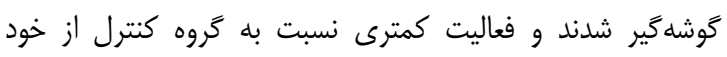

$$
\text { نشان دادند. }
$$

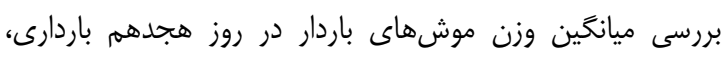

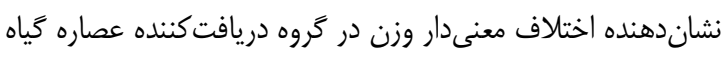

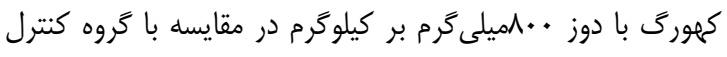

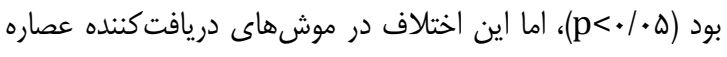

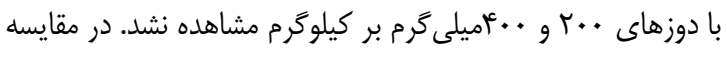

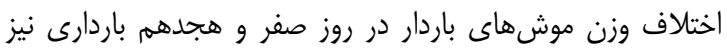

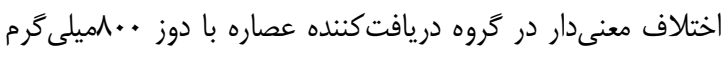

آراشيدونيكاسيد نيز ايجاد اثرات آنتى آلرزيك و آنتىهيستامينى اين كياه را توجيه مى كند[15].

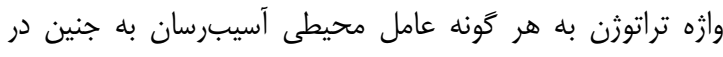

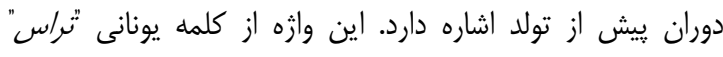
(teras)

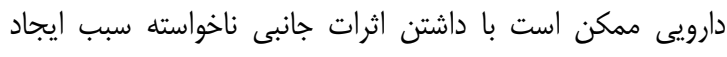

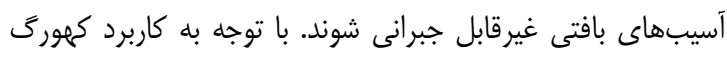

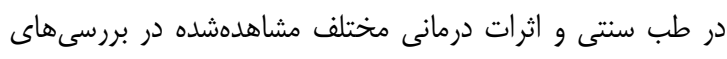

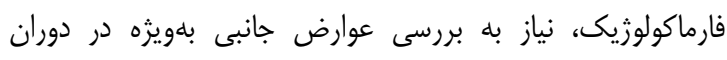

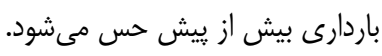

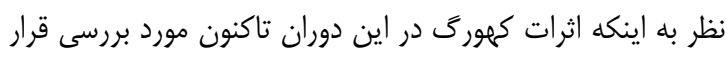

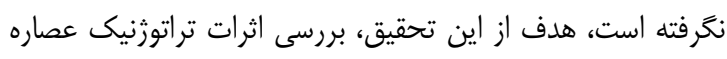

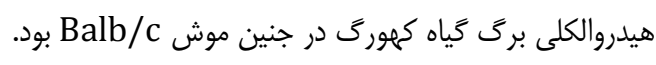

\section{مواد و روشها}

اين يزوهش تجربى در فروردين سال سوحسا انجام شد. ابتدا كياه

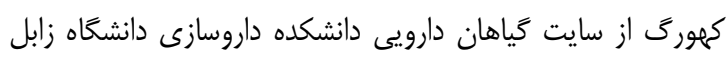

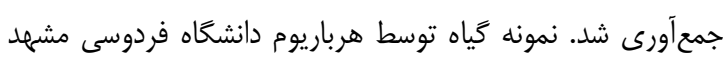
با شماره هرباريوم (FUMH)

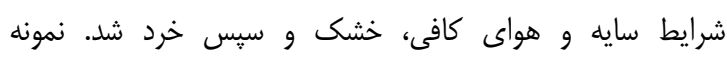

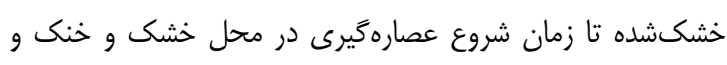

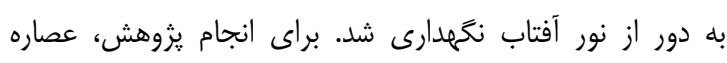

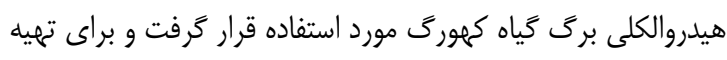

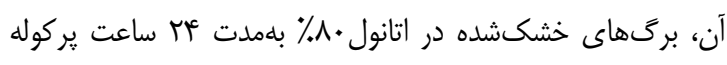
شده، سبس عصاره صاف و تغليظ شد.

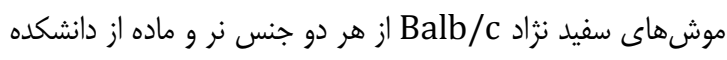

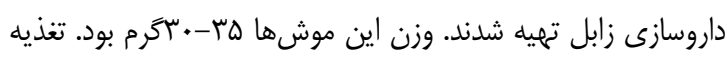

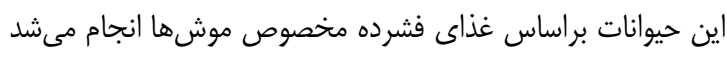

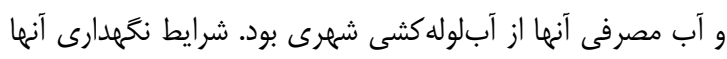

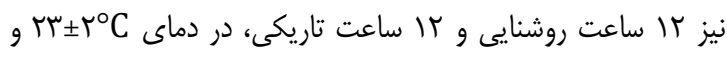

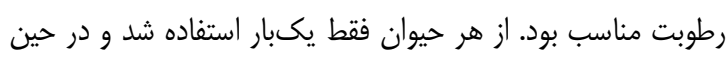

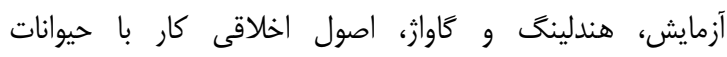

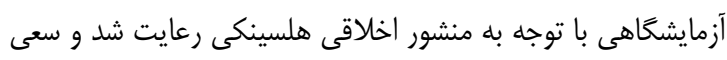

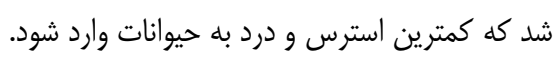

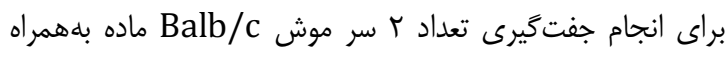

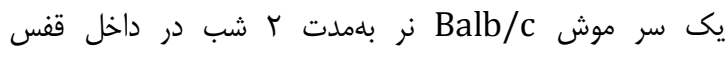

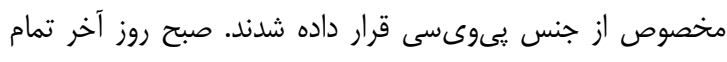

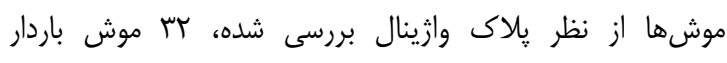

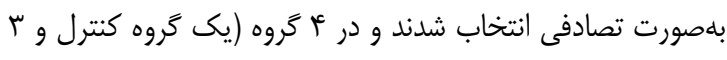

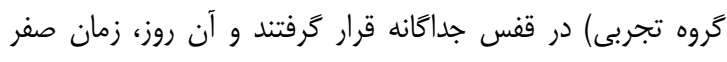

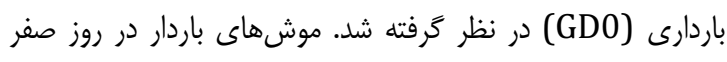
باردارى توزين شدند. 
يس از سزارين موشها در روز \ \باردارى، در بررسى ظاهرى

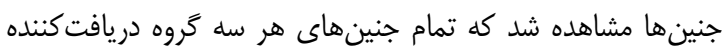

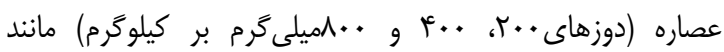

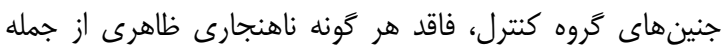

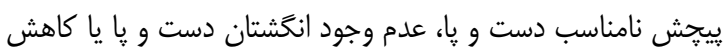

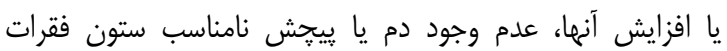

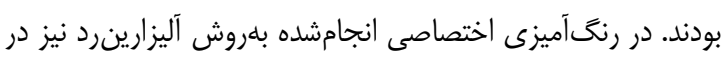

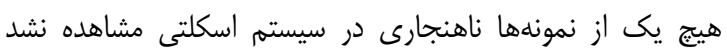

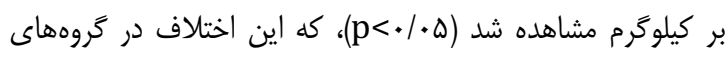

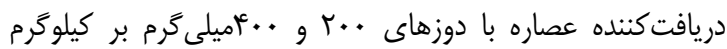

$$
\text { معنى دار نبود (جدول ( ). }
$$

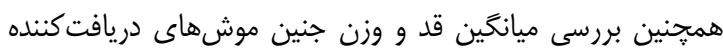

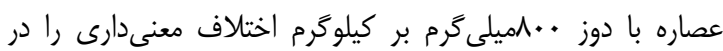

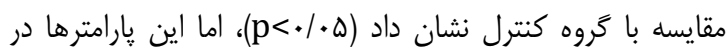

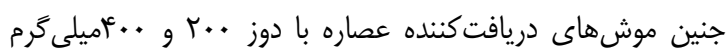

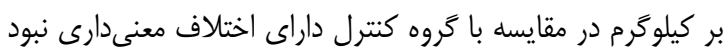

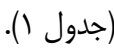

جدول () بررسى متغيرهاى مختلف در موشهاى باردار دريافت كننده عصاره هيدروالكلى كهورى در مقايسه با خروه كنترل (تعداد در هر گروه= دسر)

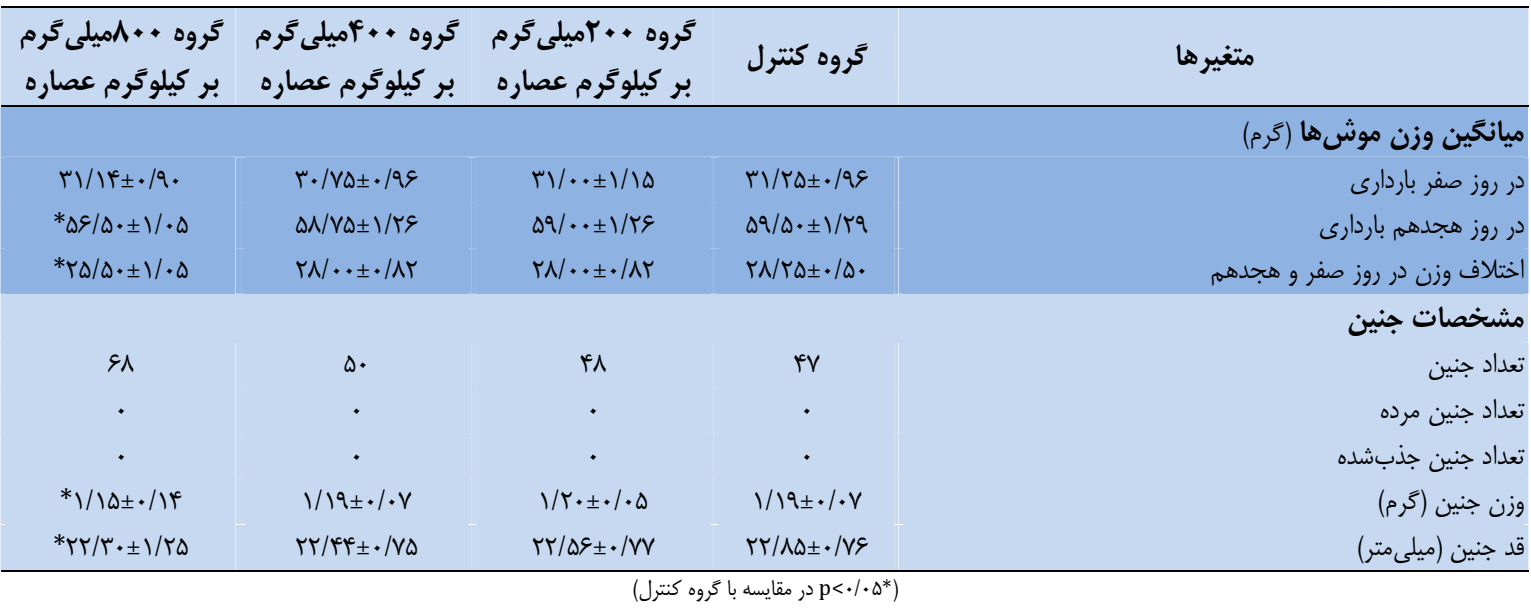

A

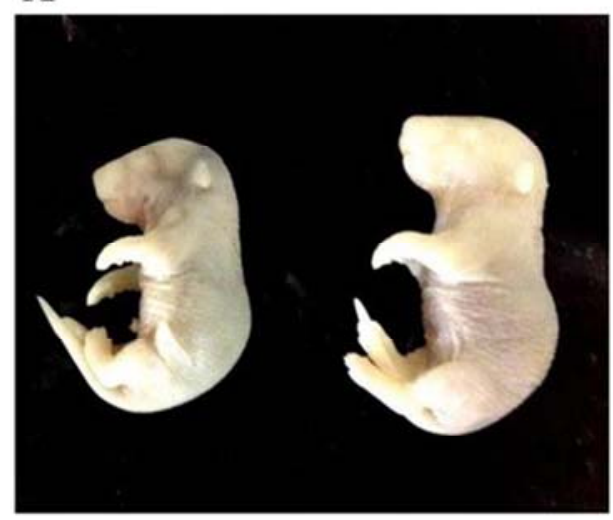

B

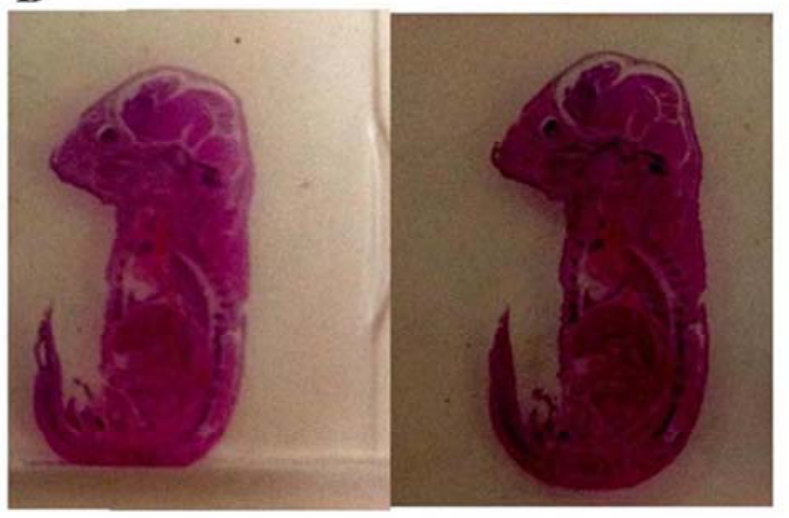

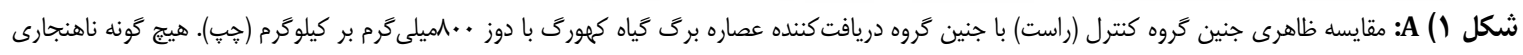

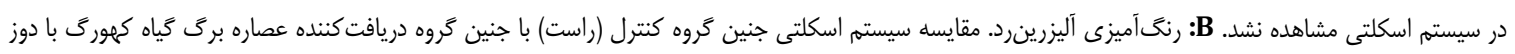

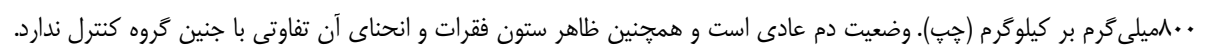

بلمخصوص در دوران باردارى دارند. اغلب زنان باردار با اين تصور

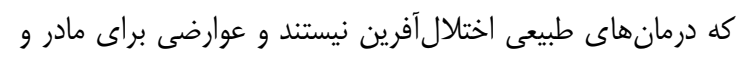

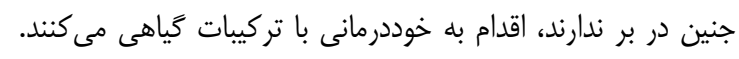

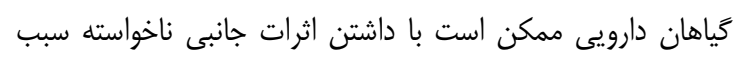

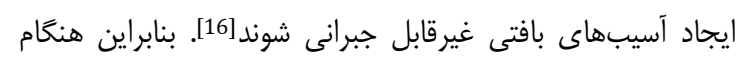

مصرف گياهان دارويى از ديرباز در ايران و ساير كشورها بين مردم

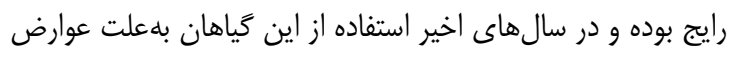

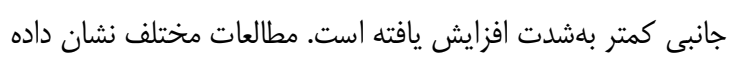

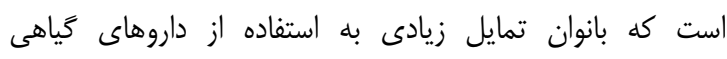
دوره rr، شماره r، بهار هوri 


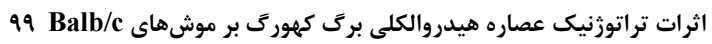

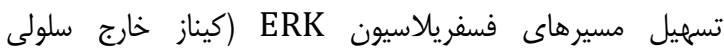

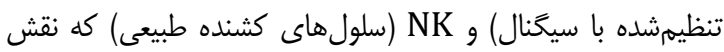

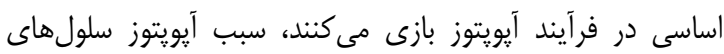
קربى مىشود [22]].

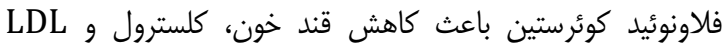

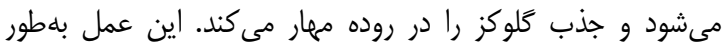

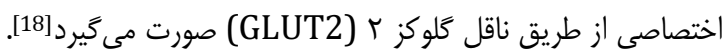

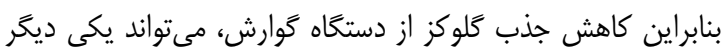

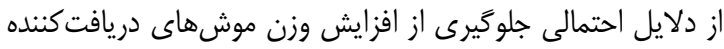

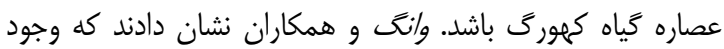

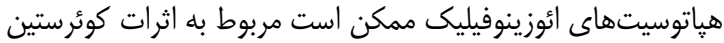

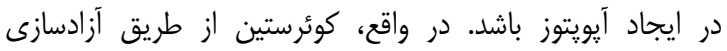

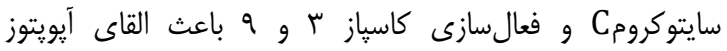

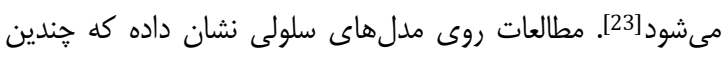

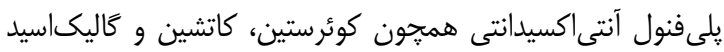

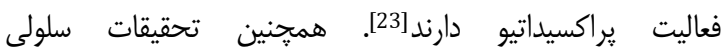
روباسزكيويكز و همكاران نشان داد كه كوئرستين در دوزهاى بالا در سلولهاى كشتشده و ميتوكندرىهاى جداشده، راديكال هاى

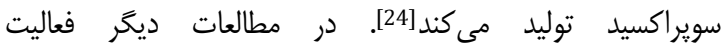

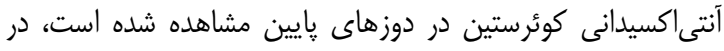

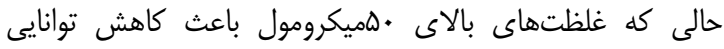

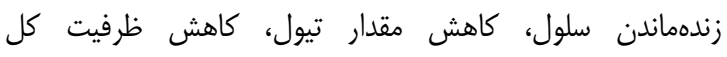

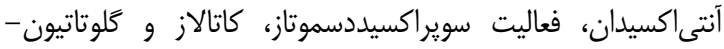

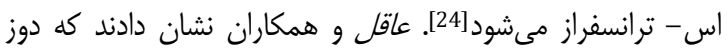

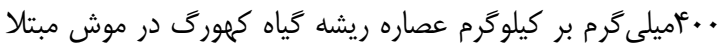

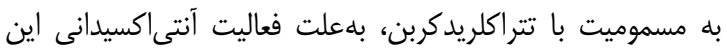

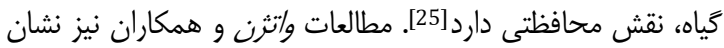

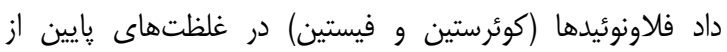
سلولهاى رده H4llE عليه مسموميت سلولى، شكستهشدن و و آيويتوز القاشده توسط يراكسيدهيدروزن محافظت

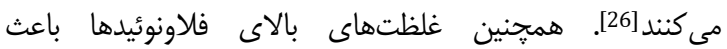

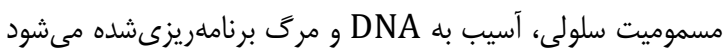

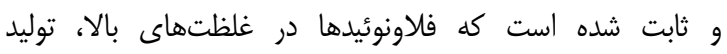

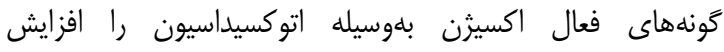

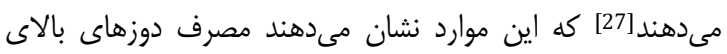

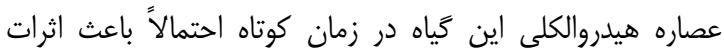

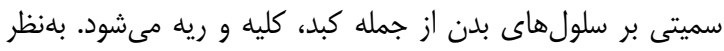
مىرسد كاهش فعاليت آنزيمهاى آنتىاكسيدان با منشا داخلى دالي در

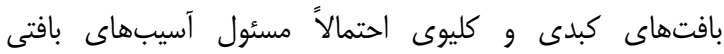

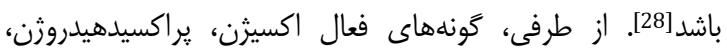

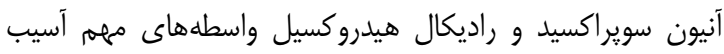

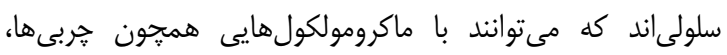

مصرف داروهاى گياهى در طول باردارى بايد اثرات سقطزايى و

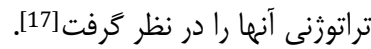

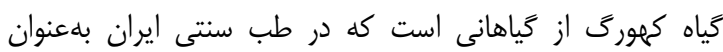

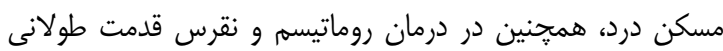
دارد و در مطالعات انجامشده نيز اثرات ضددرد دردى اين كردين

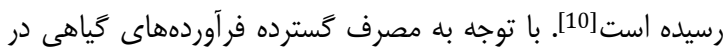
بين عموم و عوارض تراتوزنيك احتمالى ناشى از مصرف اين

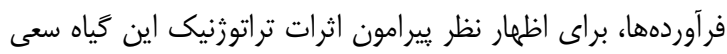

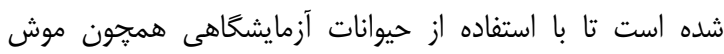
كalb/c

علمى شود.

در يزوهش حاضر موشهاى باردار دريافت كننده عصاره برى كياه

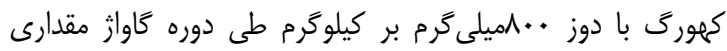

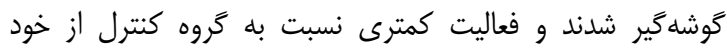

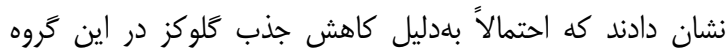

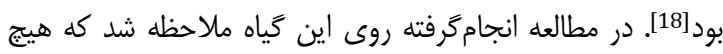

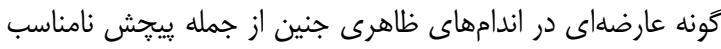

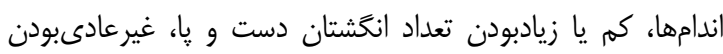

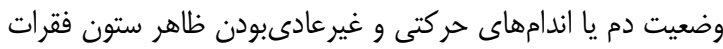

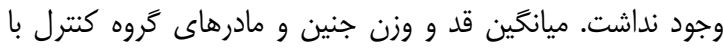

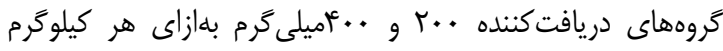

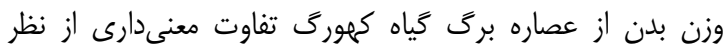

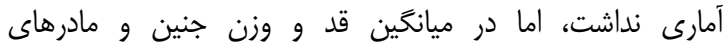

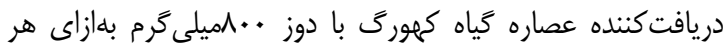

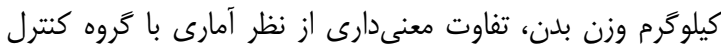

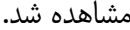

مطالعات قبلى صورت كرفته روى گياه كهورگ نشاندهنده وجود

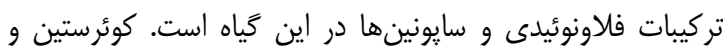

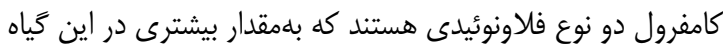

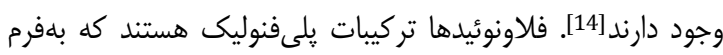

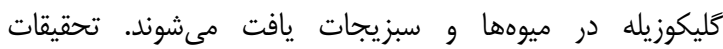

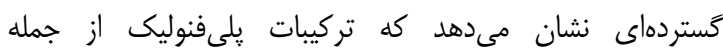

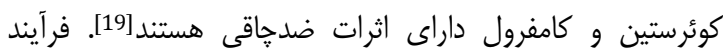
آدييوزنز توسط فاكتورهاى مختلفى از جمله SREBP (يروتئين

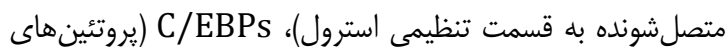

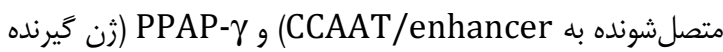

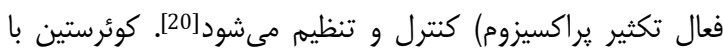

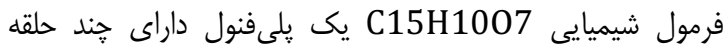

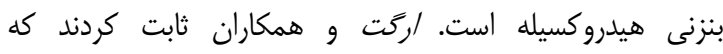

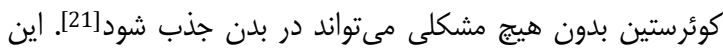

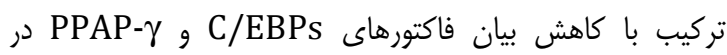

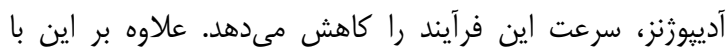


Capparis decidua on diabetic mice. J Ethnopharmacol. 2010;127(2):457-62.

4- Purohit A, Vyas KB. Hypolipidemic efficacy of Capparis decidua fruit and shoot extracts in cholesterol fed rabbits. Indian J Exp Biol. 2005;43(10):863-6.

5- Selvamani P, Latha S, Elayaraja K, Babu PS, Gupta J, Pal $\mathrm{T}$, et al. Antidiabetic activity of the ethanol extract of Capparis sepiaria $\mathrm{L}$ leaves. Indian $\mathrm{J}$ Pharm Sci. 2008;70(3):378-80.

6- Arbabian S, Jafari S, Majd A, Khosravi N. Study of structure of generative meristem and ontogeny of flower in Capparis spinosa L. J Sci Islamic Azad Univ. 2011;20(1):53-60. [Persian]

7- Mohammadi J, Mirzaei A, Delaviz H, Mohammadi B. Effects of hydroalcoholic extract of Capparis spinosa on histomorphological changes of pancreas in diabetic rats model. J Birjand Univ Med Sci. 2012;19(3):235-44. [Persian]

8- Patil SB, Naikwade NS, Magdum CS, Awale VB. Some medicinal plants used by people of Sangli district, Maharashtra. Asian J Pharm Res. 2011;1(2):42-3.

9- Kapoor B, Mishra R. Antimicrobial screening of some Capparidaceous medicinal plants of north-west rajasthan. Indian J Pharm Biol Res. 2013;1(2):20-2.

10- Heidari M, Mirshamsi M, Naghibi B, Heidari M, Vafazade J, Heidari M. Evaluation of hepatotoxicity and renal toxicity of methanolic extract of Capparis Spinosa in rats. J Shahid Sadoughi Univ Med Sci. 2010;18(1):4755. [Persian]

11- Bonina F, Puglia C, Ventura D, Aquino R, Tortora S, Sacchi A, et al. In vitro antioxidant and in vivo photoprotective effects of a lyophilized extract of Capparis spinosa L buds. J Cosmet Sci. 2002;53(6):32135.

12- Gadgoli C, Mishra SH. Antihepatotoxic activity of pmethoxy benzoic acid from Capparis spinosa. J Ethnopharmacol. 1999;66(2):187-92.

13- Eddouks M, Lemhadri A, Michel J-B. Hypolipidemic activity of aqueous extract of Capparis spinosa L. in normal and diabetic rats. J Ethnopharmacol. 2005;98(3):345-50.

14- Panico A, Cardile V, Garufi F, C.Puglia, Bonina F, Ronsisvalle G. Protective effect of Capparis spinosa on chondrocytes. Life Sci. 2005;77(20):2479-88.

15- Trombetta D, Occhiuto F, Perri D, Puglia C, Santagati $\mathrm{NA}$, Pasquale $\mathrm{AD}$, et al. Antiallergic and antihistaminic effect of two extracts of Capparis spinosa l. flowering buds. Phytother Res. 2005;19(1):29-33.

16- Keller K., Hansel R., Chandler R. Adverse effect of herbal drugs. Berlin: Springer; 1997. pp. 235-6.

17- Sarashti M, Azari P, Rafieyan M, Kheyri S. Consumption of herbal drugs in Shahrekord pregnant women. J Reprod Infertil. 2006;7(2):125-31. [Persian] 18- Nuraliev N, Vezov G. [The efficacy of quercetin in alloxan diabetes]. Eksp Klin Farmakol. 1992;55(1):42-4. [Russian]

19- Ninomiya K, Mastuda $H$, Kubo M, Morikawa T, Nishida N, Yoshikawa M. Potent anti-obese principle from Rosa canina. Bioorg Med Chem Lett. 2007;17(11):3059-64.

20- Rasuli M, Teimuri F. Iran Generic Drugs with Nursing Care. Tehran: Andishe Raphi; 2010. p. 524.

21- Erget S, Wolffram S, Bosy-Westphal A, BoeschSaadatmandi C, Wagner A, Frank J, et al. Daily quercetin concentrations in healthy humans. J Nutr. 2008;138(9):1615-21.

$$
\begin{aligned}
& \text { يروتئينها، اسيدهاى نوكلئيك، كربوهيدراتها و اسيدهاى هارى هرب } \\
& \text { غيراشباع در غشاى سلول واكنش دهند و پِ إن از شروع واكنش }
\end{aligned}
$$

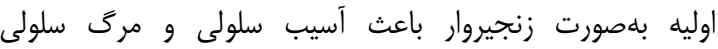

$$
\begin{aligned}
& \text { شوند[28]. همجنين مطالعات انجامشده نشان داده است كه تعدادى بـى } \\
& \text { از آنتىاكسيدانها مثل كوئرستين مىتوانند از فعاليت آنزيمهاى } \\
& \text { سيتوكروم P450 ممانعت بهعمل آورند و باعث آستون آسيب سلولى آلى } \\
& \text { بلهورت نكروز و آيويتوز شوند [29]. }
\end{aligned}
$$

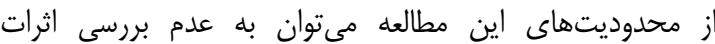

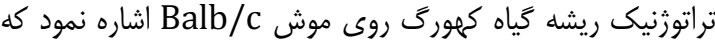

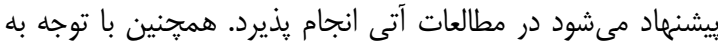

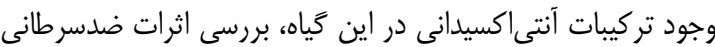

$$
\begin{aligned}
& \text { آن يِيشنهاد مى شودود }
\end{aligned}
$$

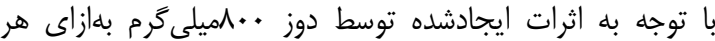

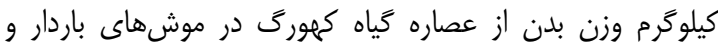

$$
\begin{aligned}
& \text { جنين أنها و از طرفى عدم مطالعه كافى اثرات اين گياه بر انسان، لذا تهاه }
\end{aligned}
$$

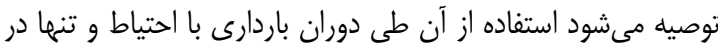

$$
\begin{aligned}
& \text { صورت تجويز نزشك معالج صورت گيرد. } \\
& \text { نتيجه تيرى } \\
& \text { دوز •مميلى گرم بر كيلوگرم عصاره هيدروالكلى برگ كهورگ بر }
\end{aligned}
$$

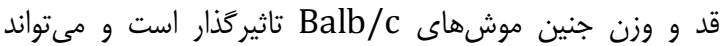

$$
\begin{aligned}
& \text { داراى اثرات تراتوزنيك بر جنين باشد. }
\end{aligned}
$$

تشكر و قدردانى: نويسندگًان از دانشكده داروسازى دانشگاه

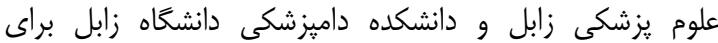
همكارى در اين يزوهش كمال تشكر و قدردانى را دارند. تاييديه اخلاقى: يروتكل اين يزوهش براساس قورانين برون بين المللى

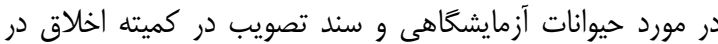
يزوهشهاى علوم يزشكى (BP-QP-106-01) به انجام رسيد. تعارض منافع: هيج گونه تعارض منافع توسط نويسندگان بيان

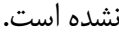

منابع مالى: اين مطالعه با هزينه گَروه فارماكوگنوزى دانشكده

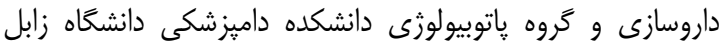

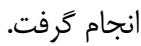

\section{منابع}

1- Zargari A. Medicinal Plants. Tehran: Tehran University Press; 1997. pp. 258-62.

2- Rajesh P, Selvamani P, Latha S, Saraswathy A, Kannan V. A review on chemical and medicobiological applications of capparidaceae family. Pharmacogn Rev. 2009;3(6):378-86.

3- Sharma B, Salunke R, Balomajumder C, Daniel S, Roy P. Anti-diabetic potential of alkaloid rich fraction from 
اثرات تراتوزنيك عصاره هيدروالكلى برك كهورَى بر موشهاى Balb/c 1.1 2007;6(4):285-90.

26- Watjen W, Michels G, Steffan B, Niering P, Chovolou Y, Kampkotter A, et al. Low concentrations of flavonoids are protective in rat H4IIE cells whereas high concentrations cause DNA damage and apoptosis. J Nutr. 2005;135(3):525-31.

27- Gaspar J, Rodrigues A, Laires A, Silva F, Costa S, Monteiro MJ, et al. On the mechanisms of genotoxicity and metabolism of quercetin. Mutagenesis. 1994;9(5):445-9.

28- Birdane Y, Buyukokuroglu M, Birdane F, Cemek M, Yavuz H. Anti-inflammatory and antinociceptive effects of Melissa officinalis L. in rodents. Revue Med Vet. 2007;158(2):75-81.

29- Obermeier MT, White RE, Yang CS. Effects of bioflavonoids on hepatic P450 activities. Xenobiotica. 1995;25(6):575-84.

22- Kuroyanagi K, Kang MS, Goto T, Hirai S, Ohyama $\mathrm{K}$, Kusudo T, et al. Citrus auraptene acts as an agonist for PPARs and enhances adiponectin production and MCP-1 reduction in 3T3-L1 adipocytes. Biochem Biophys Res Commun. 2008;366(1):219-25.

23- Wang I-K, Lin-Shiau S-Y, Lin J-K. Induction of apoptosis by apigenin and related flavonoids through cytochrome c release and activation of caspase- 9 and caspase-3 in leukaemia HL-60 cells. Eur J Cancer. 1999;35(10):1517-25.

24- Robaszkiewicz A, Balcerczyk A, Bartosz G. Antioxidative and prooxidative effects of quercetin on A549 cells. Cell Biol Int. 2007;31(10):1245-50.

25- Aghel N, Rashidi I, Mombeini A. Hepatoprotective activity of Capparis spinosa root bark against $\mathrm{CCl}_{4}$ induced hepatic damage in mice. Iran J Pharm Res. 